\title{
Postmitotic, Postmigrational Expression of Tyrosine Hydroxylase in Olfactory Bulb Dopaminergic Neurons
}

\author{
John H. McLean ${ }^{1}$ and M. T. Shipley ${ }^{1,2}$ \\ 'Department of Anatomy and Cell Biology, Division of Neurobiology, and ${ }^{2}$ Department of Neurosurgery, University of \\ Cincinnati College of Medicine, Cincinnati, Ohio 45267-0521
}

The developmental expression of tyrosine hydroxylase (TOH) was studied in a large, specific population of dopaminergic (DA) neurons in the main olfactory bulb (MOB) of the rat. These DA neurons comprise an anatomically distinctive population that has been well characterized in the adult hamster (Davis and Macrides, 1983) and rat (Halasz et al., 1981; Baker et al., 1983, 1984). We addressed a basic question in developmental neurobiology: What factors regulate the expression of neuronal transmitter phenotype during development? Olfactory bulb DA neurons are born in the ventricular and subependymal zones and migrate through all intervening layers to the most superficial layer in the bulb (Altman, 1969; Bayer, 1983). The time of TOH expression in these neurons was determined using immunohistochemlstry and light microscopic image-analysis techniques. The results indicate that TOH phenotype is not expressed when the cells are born in the subependymal zone nor during their migration to the periglomerular region but only after they reached their final destination, the glomerular layer. This suggests that epigenetic factors associated with the glomeruli initiate the expression of the key transmitter synthesizing enzyme in these neurons.

Primary olfactory neurons in the nasal epithelium project exclusively to glomeruli of the MOB; removal of this input in adult rats (Kawano and Margolis, 1982; Baker et al., 1983, 1984), mice (Nadi et al., 1981; Baker et al., 1983), dogs (Nadi et al., 1981), and hamsters (Kream et al., 1984) appears to down-regulate the expression of the $\mathrm{TOH}$ in periglomerular cells. The present results suggested that the input from the primary olfactory nerve is also necessary for the initial expression of the TOH phenotype. In support of this notion, we found that lesions of the olfactory nerve during the first postnatal week caused a significant reduction in the number of TOH-positive juxtaglomerular neurons in the following weeks. Thus, the olfactory nerve appears to be necessary for both the initiation and maintenance of TOH expression in olfactory bulb neurons. These findings suggest that specific cell-cell interactions play a key role in CNS neuronal transmitter phenotype regulation.

\footnotetext{
Received July 29, 1987; revised Jan. 12, 1988; accepted Feb. 17, 1988.

We wish to thank E. Sieloff, M. Lazoff, B. Frydel, K. Wilburn, and Y. Tsai for technical assistance. We are also grateful to P. Hug and J. Luna, who wrote programs used in the image analysis. Supported by NIH NS 23348 and U.S. Army DAMD17-86-C-6005.

Correspondence should be addressed to Dr. Michael T. Shipley at the above address.

Copyright (C) 1988 Society for Neuroscience $0270-6474 / 88 / 103658-12 \$ 02.00 / 0$
}

The present study also demonstrated that there are significant postnatal changes in the number, size, and distribution patterns of MOB DA neurons. From birth to adulthood there is a linear increase of over 100 -fold in the number of neurons expressing the TOH phenotype. There are about 1000 DA neurons per bulb at birth; in adulthood there are approximately 150,000 DA neurons per bulb. The average size of the TOH-immunoreactive cells decreases during development: from $12.1 \pm 0.5 \mu \mathrm{m}$ in the neonate to approximately $10.0 \pm 0.5 \mu \mathrm{m}$ in the adult MOB. This decrease in average size may be related to the fact that there are 2 populations of DA neurons in the adult MOB (Halasz et al., 1981; Baker, 1986; present report). Size histograms of developing and mature MOB DA neurons were generated, and the results suggest that the first $\mathrm{MOB}$ neurons to express the dopamine phenotype are probably external tufted cells, which are born earlier than the smaller, more numerous periglomerular neurons which express the phenotype later.

The steady, prolonged increase in the number of neurons expressing the DA phenotype in $\mathrm{MOB}$ suggests that these neurons have a progressively important role during the development of olfactory function. This may be related to the steadily increasing ability of rats to discriminate different odors during the first postnatal month (Alberts, 1981).

Determination of the factors that regulate the expression of the neurotransmitter phenotype in developing neurons is a central issue in developmental neurobiology. Most experiments to date have examined neurons in the PNS or in culture. These studies indicate that epigenetic factors such as the integrity of target tissue, presence of afferent inputs, and possibly soluble "trophic" molecules may influence the expression of neurotransmitter phenotype (Furshpan et al., 1976; Reichardt and Patterson, 1977; LeDouarin, 1980; Potter et al., 1981). Thus, it has been hypothesized that epigenetic factors in the PNS influence the initiation and regulation of neurotransmitter phenotype. Much less is known about the factors that regulate the expression of neurotransmitters and peptides in the CNS, doubtless because of the complex connections of central neurons and because they are more difficult to manipulate experimentally than PNS neurons.

One approach to the question of phenotype regulation in the $\mathrm{CNS}$ is to determine when and where the transmitter phenotype is initially expressed during development, i.e., is the transmitter expressed at mitosis, during migration, or when the cell inserts into its definitive circuit matrix? Specht et al. (1981a, b) studied developing pros- through rhombencephalic DA neurons in pre- 
natal rats and suggested that some DA neurons express their phenotype during migration. In the brain stem it is difficult to know when migrating DA neurons begin to make and receive contacts. Thus, it is possible that DA neurons that are still migrating have significant interactions with their appropriate pre- and postsynaptic affiliates or have transient contacts with cells that influence the expression of transmitter phenotype. For the DA neurons of the olfactory bulb, it is possible to make a clearer distinction between the mitosis, migration, and contact stages because these neurons are born in the subependymal zone and migrate radially to the most superficial cell layer of the bulb (Shimada, 1966; Altman, 1969), where they establish their definitive synaptic contacts. Additionally, the vast majority of the DA neurons of the olfactory bulb develop postnatally, a circumstance that facilitates their study and the manipulation of their pre- and postsynaptic affiliates. Thus, we know where these neurons are born, their developmental timc coursc, and their route of migration. It has also been demonstrated that the dopamine (DA) levels and tyrosine hydroxylase ( $\mathrm{TOH}$ ) activity in the adult bulb are influenced by epigenetic factors (Nadi et al., 1981; Kawano and Margolis, 1982; Brunjes et al., 1985). TOH immunoreactivity in juxtaglomerular neurons (comprising periglomerular and external tufted cells) in the adult bulb is severely reduced or eliminated subsequent to removal of primary olfactory nerve (PON) input to the olfactory bulb glomeruli (Baker et al., 1983, 1984; Kream et al., 1984). Thus, the olfactory nerve has a regulatory action on $\mathrm{TOH}$ activity in the adult bulb. It is possible, therefore, that the developmental induction of $\mathrm{TOH}$ expression is also influenced by olfactory nerve input. In the present study, we lesioned the olfactory nerve in developing animals to assess its role in the initiation on the $\mathrm{TOH}$ phenotype.

The purposes of this study, therefore, were to specify the postnatal development of DA neurons in main olfactory bulb (MOB) using immunohistochemistry and lesions of the olfactory nerve to determine if the TOH phenotype is expressed at mitosis, during migration, or inserted (Fig. 1). The central hypothesis is that induction of the TOH phenotype depends upon specific postmitotic, postmigrational cell-cell interactions.

\section{Materials and Methods}

Animal and tissue preparation. Sprague-Dawley rats aged 1, 2, 3, 4, 5, $8,10,11,14,16,22,28,32,37,50,60$, and $64 \mathrm{~d}$ or older adults were used in this study. Postnatal day 1 (P1) is defined as the day of birth, while adults are considered P60 or older. Two to five rats were used at each age studied. The rats were anesthetized deeply with sodium pentobarbital and perfused transcardially with saline (room temperature) for $2 \mathrm{~min}$. The saline rinse was followed by perfusion with $4 \%$ paraformaldehyde and $0.5 \%$ glutaraldehyde in $0.1 \mathrm{M}$ phosphate buffer $(\mathrm{pH}$ 7.4) for $30 \mathrm{~min}(500 \mathrm{ml})$. Brains were removed from the skull, left in the fixative for at least $1 \mathrm{hr}$, and placed in phosphate-buffered $20 \%$ sucrose overnight.

Immunohistochemistry. Thirty-micron-thick frozen sections of the olfactory bulb were cut in the transverse plane and placed in $0.1 \mathrm{M}$ PBS at $\mathrm{pH}$ 7.4. Free-floating sections were processed for immunohistochemistry using the following protocol: Scetions werc (1) rinsed in $0.1 \mathrm{M}$ PBS, (2) incubated in primary antiserum or without primary antibody in $0.1 \%$ Triton X-100, 2\% normal goat serum (NGS) in PBS for 15-40 hr in the cold on a shaker table, (3) rinsed $2 \times 10 \mathrm{~min}$ in PBS, (4) incubated in goat anti-rabbit IgG (Cappel) diluted 1:100 in the same diluent as in step 1 for $1 \mathrm{hr}$ at room temperature, (5) rinsed $2 \times 10 \mathrm{~min}$ in PBS, and (6) incubated $1 \mathrm{hr}$ in rabbit peroxidase-antiperoxidase (Dakopak, Accurate Chemicals, Inc.) diluted $1: 100$ in same diluent as in step 1 . Procedures 3-6 were sometimes repeated. After $2 \times 10$ min rinses in PBS, sections were incubated for $10-20 \mathrm{~min}$ in a PBS containing $0.05 \%$ diaminobenzidine dihydrochloride and $0.01 \% \mathrm{H}_{2} \mathrm{O}_{2}$. Sections were then

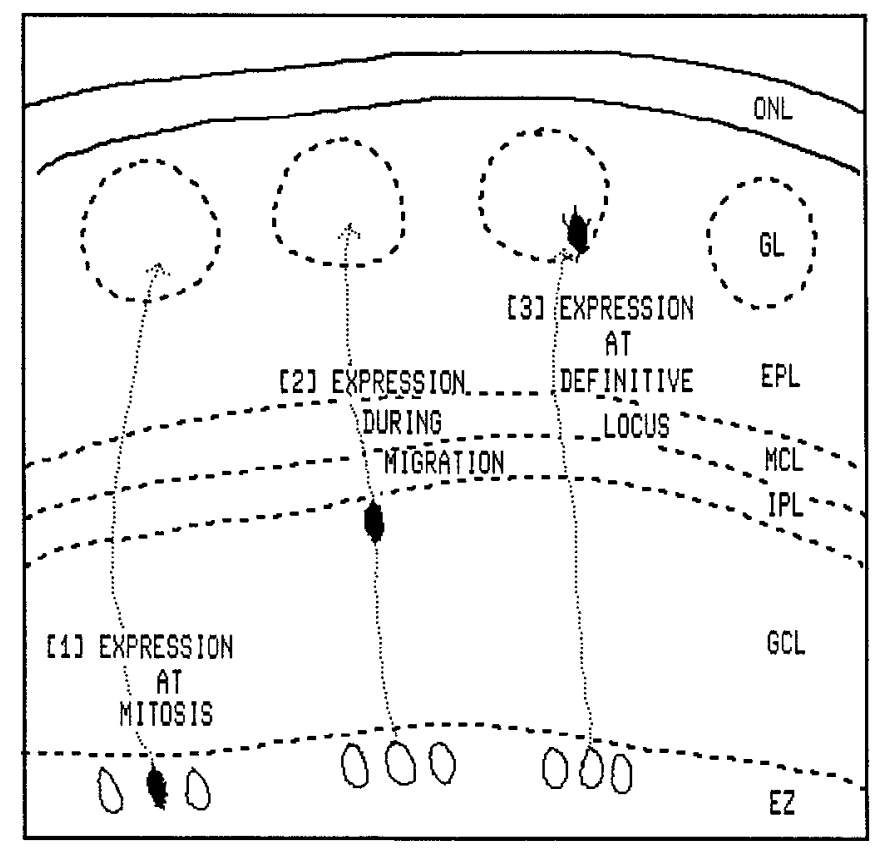

Figure 1. Hypothesis of when neurons in MOB could begin to express the TOH enzyme during development. $E P L$, external plexiform layer; $E Z$, ependymal/subependymal zone; $G C L$, granule cell layer; $G L$, glomerular layer; $I P L$, internal plexiform layer; $M C L$, mitral cell layer.

rinsed $2 \times 10 \mathrm{~min}$ in phosphate buffer, mounted on subbed slides, rinsed in distilled water, dehydrated, and coverslipped.

The primary antibody was polyclonal rabbit anti-TOH diluted 1:5001:1000. The antibody was a generous gift from Dr. Tom Finger and has been characterized previously for specificity (Morita and Finger, 1987). The TOH immunoreactivity is specific for DA neurons but may also detect neurons containing catecholamines other than dopamine. Thus, some sections of MOB were incubated with an antibody to dopaminebeta-hydroxylase, a requisite enzyme for noradrenergic (NE) neurons or with antibodies to PNMT to detect potential epinephrine (E) neurons. No NE or E neurons were detected in MOB at any of the ages studied. Thus, the anti-TOH appears to label only DA neurons in MOB. Additional evidence that the TOH-immunoreactive (IR) staining is a definitive marker for MOB DA cells is provided by biochemical studies showing that TOH is closely associated with DA levels in the olfactory bulb glomerular layer (Nadi et al., 1981).

Nissl-stained sections. The location and distribution of TOH-IR neurons at each developmental age were correlated with the developing cytoarchitecture of MOB in sections that were cut serially in the transverse plane at $40 \mu \mathrm{m}$ and stained with cresyl violet. In addition, some sections that had been processed for $\mathrm{TOH}$ were counterstained with cresyl violet for Nissl so that the relative abundance of TOH-IR cells versus non-TOH-IR periglomerular cells at different stages of development could be assessed directly.

Olfactory nerve lesions. Five rat pups at $\mathrm{P} 3-7$ were anesthetized with $0.02 \mathrm{ml}$ of a mixture of 9 parts ketamine $(40 \mathrm{mg} / \mathrm{kg})$ and 1 part acepromazine $(0.2 \mathrm{mg} / \mathrm{kg})$. The cartilage dorsal to the nasal epithelium was removed on one side, the epithelium was exposed by a parasagittal incision, and a gelfoam pledget containing $1-2 \mu \mathrm{l}$ of $0.17 \mathrm{M} \mathrm{ZnSO}_{4}$ was placed in the nasal cavity. A similar procedure (nasal irrigation with $\mathrm{ZnSO}_{4}$ ) effectively and permanently destroys the PONs whose axons comprise the olfactory nerve (rat: Margolis et al., 1974; hamster: Kream et al., 1984). Following surgery, the pups were kept warm until they were ambulatory. They were then returned to their mother until the time of sacrifice or weaning. All rats were housed and maintained in AAALAC approved facilities in the Department of Laboratory Animal Medicine at the University of Cincinnati. After a 7-14 d survival, the animals were sacrificed, and their brains were processed for immunohistochemistry as described above.

Image analysis. Sections of the rat olfactory bulb were examined under bright-field optics and imaged with a Newvicon TV camera through a digital real-time video processor (Hughes Aircraft Co., Image Model 

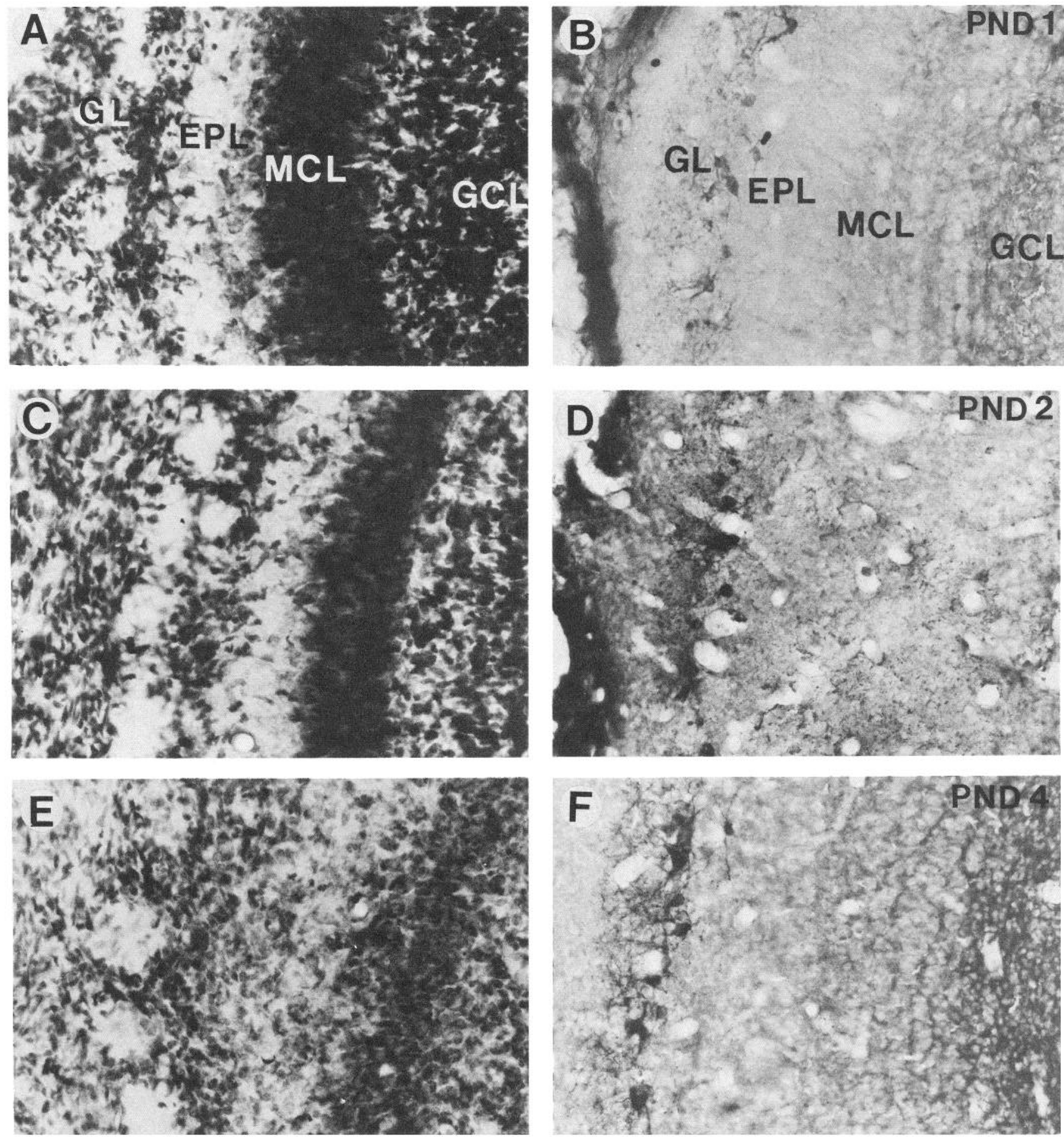

Figure 2. A-P, Bright-field photomicrographs of Nissl-stained (left photos) and TOH-IR (right photos) transverse sections obtained at different postnatal ages. The intensity of TOH-IR staining in cells is relatively consistent across different ages. Scale bar, $100 \mu \mathrm{m}$. For abbreviations, see Figure 1.

794) and fed to a Magiscan 2A (Joyce-Loebl) image-analysis system. The labeled neurons were analyzed throughout the thickness of the section. The image-analysis system displays live images on a $512 \times 512$ high-resolution monitor. Reconstruction of live images of $1024 \times 1024$ pixels and greater has been made possible by a program that controls movements of the microscope stage and focus control. Thus, the Magiscan system is used to identify, precisely plot, and measure all labeled neurons in relation to selected anatomical landmarks; cytoarchitectonic boundaries are also plotted. The area, perimeter, length, and breadth of labeled neurons were measured, and statistical analysis of the results was performed using the Student $t$ test to determine if there were differences in juxtaglomerular DA neurons in different parts of the glomerular region and/or at different developmental ages.

\section{Results}

The postnatal development of DA neurons in MOB is detailed below. Because the developmental patterns and numbers of 

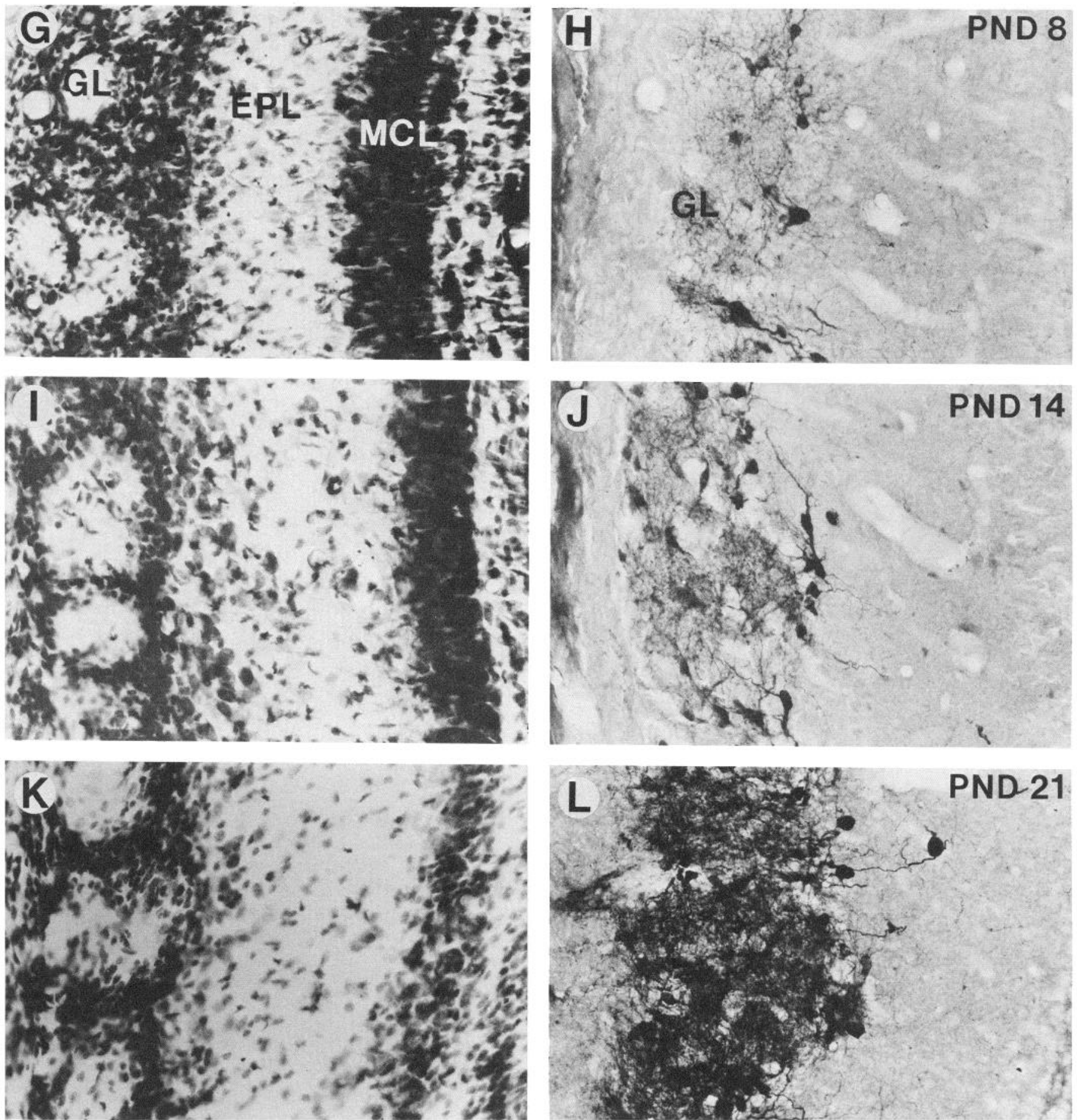

TOH-IR cells are similar at some developmental ages, results from these ages were grouped for purposes of description. Most of the results and illustrations are based on observations of mid-rostrocaudal levels of MOB unless otherwise stated, although all rostrocaudal levels of MOB were analyzed. To correlate the locations of TOH-IR neurons with the cytological development of the olfactory bulb, brief descriptions of Nisslstained sections of MOB at different stages of development are presented for each age group first, followed by an account of the TOH-IR neurons.

\section{P1-8 stage}

Nissl staining. In Nissl-stained sections of the MOB, only a few glomeruli of P1 rats are visible, and they are very small (Fig. $2 A$ ). These glomeruli are up to $35 \mu \mathrm{m}$ in diameter and are surrounded by many small darkly stained presumptive neurons and/or glia. By P2, more glomeruli are visible, and some are as large as $50 \mu \mathrm{m}$ in diameter. The external plexiform layer is about $50 \mu \mathrm{m}$ thick and contains numerous small neurons (Fig. 2C). By the end of the first postnatal week, most glomeruli are visible, 

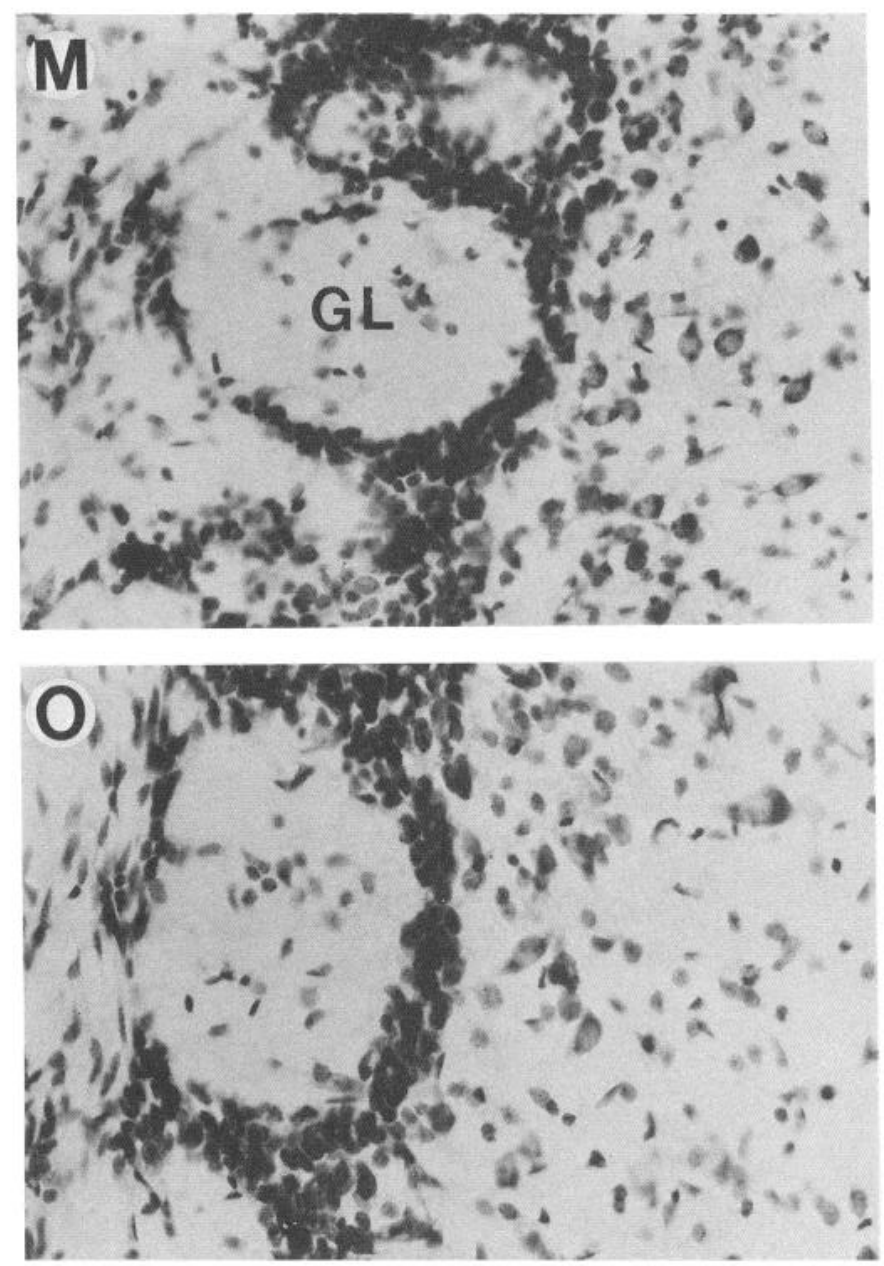

and the largest of them have diameters of 70-80 $\mu \mathrm{m}$. The external plexiform layer is about $75-100 \mu \mathrm{m}$ thick. The number of neurons in the external plexiform layer increases substantially around P4 (Fig. 2E). This increase may be the result of migrating juxtaglomerular neurons since a large proportion of these interneurons are born during this period (Bayer, 1983) and are probably en route from their birthplace in the ependymal zone to their final destination in the glomerular layer. By P8, the number of neurons surrounding the glomeruli or between glomeruli has increased substantially so that they are packed about 10 deep between glomeruli or between glomeruli and the external plexiform layer (Fig. $2 G$ ).

TOH immunoreactivity. From P1 through P8, TOH-IR neurons are scattered around the circumference of the bulb and are generally located on the deep aspect of glomeruli (Figs. 2, 3). No TOH-IR neurons were visible in the mitral cell layer or deeper layers of the bulb. Most of the TOH-IR cells were between $11.5-13 \mu \mathrm{m}$ in long axis (Table 1). At P1, the dendrites of individual labeled neurons are well developed and often ramify within a single glomerulus (Fig. $2 B$ ). At this early age, these dendritic ramifications are readily visualized because typically only one neuron is associated with each glomerular profile; in a few instances the dendrites enter more than one glomerulus. During the latter part of the first postnatal week and at subsequent ages, the number of DA neurons/glomerulus increases
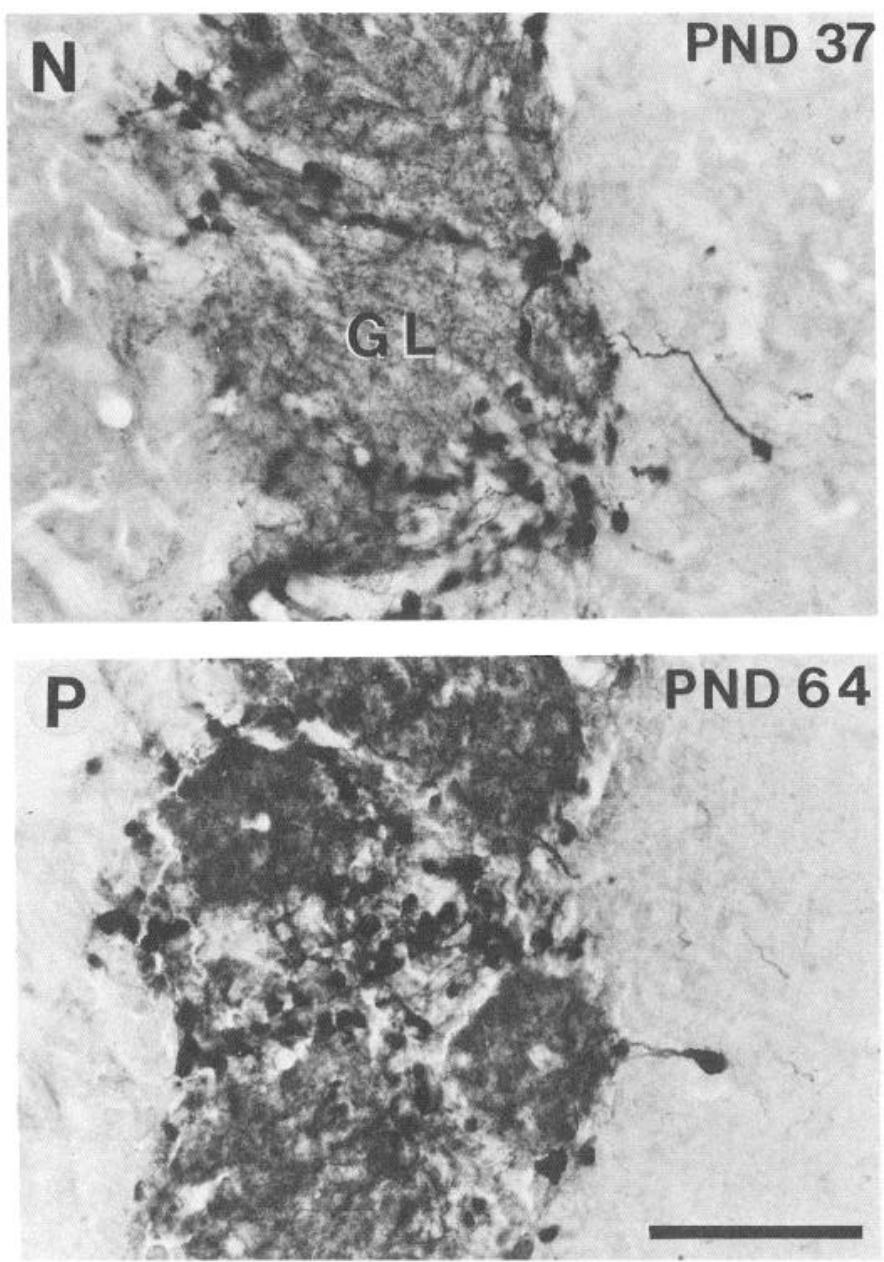

rapidly, and it becomes progressively more difficult to follow dendrites belonging to specific neurons and, thus, to determine what proportion of the neurons extend their dendrites into more than one glomerulus.

\section{P14-22 stage}

Nissl staining. The glomeruli of rats in the third week are substantially larger than those of rats in the first week of postnatal life. Glomerular diameters range from 50 to $125 \mu \mathrm{m}$. There are fewer neurons intervening between glomeruli by this time: $5-6$ compared with 7-10 at P8. The decrease in the packing of interglomerular neurons may reflect the reduced rate of periglomerular cell birth and migration of neurons by this developmental age (Bayer, 1983), which would cause the thinning out of cells as they relocate to surround the growing glomeruli; alternatively, it could represent cell death. By this time the external plexiform layer has expanded to up to $200 \mu \mathrm{m}$ in thickness and contains cells of many sizes.

TOH immunoreactivity. Many more TOH-IR neurons are present during this period than at P1-8 (Figs. 2 and 3). The neurons are predominantly located in the deeper portions and to a lesser extent around the remaining circumference of the glomeruli. The range of cell sizes at this age is from 6 to $20 \mu \mathrm{m}$, with the mean around $11.5 \mu \mathrm{m}$ (Table 1). On average, 5 neurons are associated with individual glomerular profiles in $30-\mu \mathrm{m}$ - 


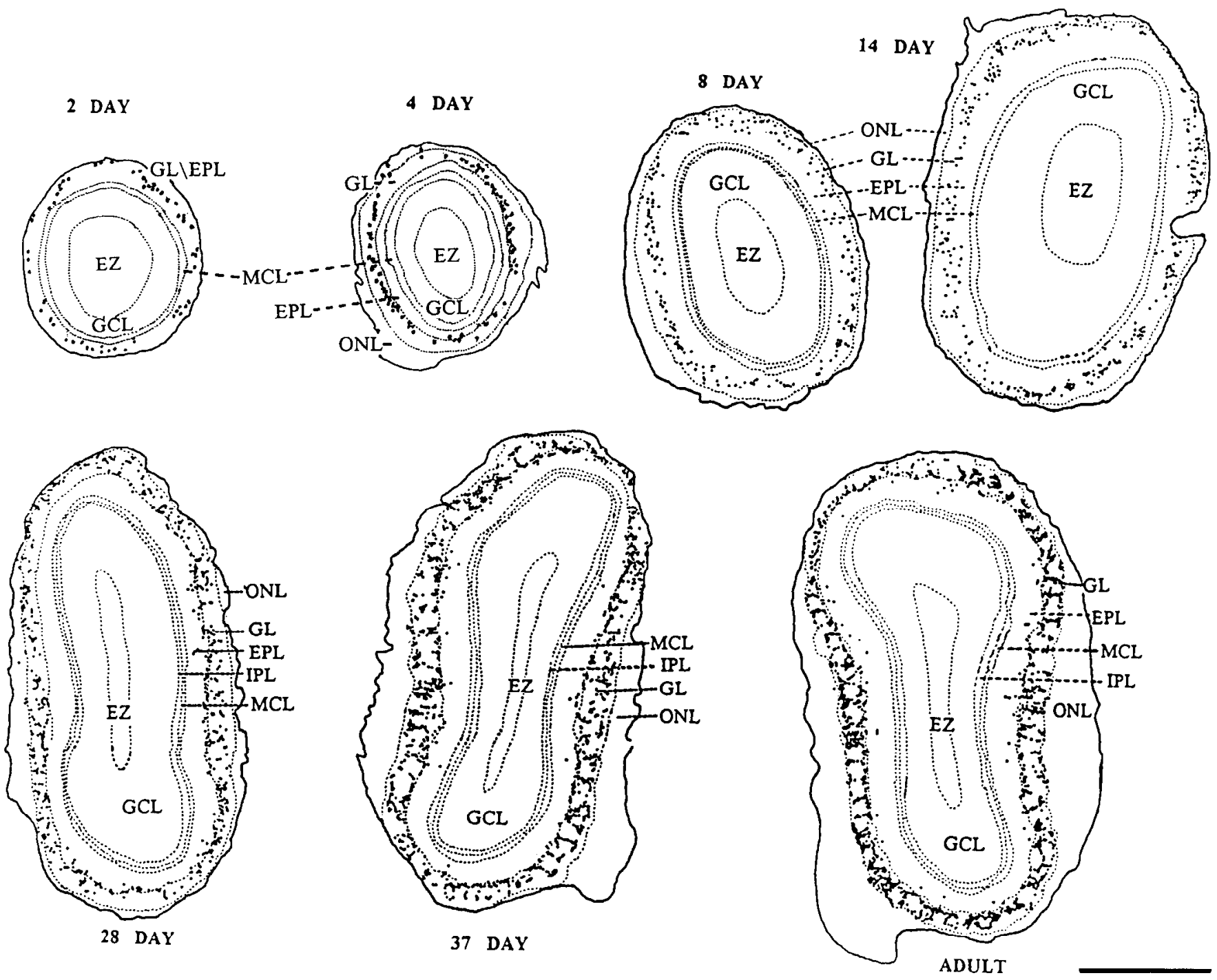

Figure 3. Computer-assisted reconstruction of transverse sections through the MOB showing the distribution of TOH-IR neurons during development. The labeled neurons are noted by dots. Scale bar, $1 \mathrm{~mm}$. For abbreviations, see Figure 1.

thick transverse sections, although some glomerular profiles have more and some still lack DA neurons. There was no observable systematic relationship between the size or location of glomeruli with DA neurons and those lacking DA cells at those ages.

\section{P32-40 stage}

Nissl staining. The olfactory bulb continues to increase in size during this period, and the size of glomeruli also increases to up to $150-200 \mu \mathrm{m}$ in diameter. Juxtaglomerular cells are packed 3-4 deep between glomeruli by this stage.

TOH immunoreactivity. During this $32-40 \mathrm{~d}$ stage, the distribution of TOH-IR neurons begin to look much like that found in the adult. The average size of the juxtaglomerular TOH-IR cells has decreased compared with earlier stages of development (Table 1). The main differences between the TOH-IR neuron distribution at P37 and in adults are (1) the size of the glomeruli, which is slightly larger in the adult, and (2) the number of TOHIR neurons observed in each section, which is greater in the adult (Table 2). Basically, however, the pattern of DA juxtaglomerular neurons is similar to adult patterns by the fifth postnatal week.

\section{Adult stage $(>P 60)$}

Nissl staining. The glomeruli in the adult MOB range from 100 to $160 \mu \mathrm{m}$ in diameter. The glomeruli are surrounded by small cells packed 1-2 layers thick except in interglomerular regions, and the decp aspect of glomeruli where multiple layers of small neurons occupy the neuropil (Fig. 2O). The glomeruli on both

\begin{tabular}{|c|c|c|c|}
\hline $\begin{array}{l}\text { Postnatal } \\
\text { age } \\
\text { (d) }\end{array}$ & No. of rats & $\begin{array}{l}\text { Total neurons } \\
\text { measured } \\
(n)\end{array}$ & $\begin{array}{l}\text { Length } \\
(\mu \mathrm{m}, \text { mean } \pm \mathrm{SD})\end{array}$ \\
\hline 1 & 5 & 86 & $12.1 \pm 0.5$ \\
\hline 4 & 2 & 67 & $12.5 \pm 0.1$ \\
\hline 8 & 5 & 187 & $12.4 \pm 0.2$ \\
\hline 15 & 2 & 184 & $11.5 \pm 0.4$ \\
\hline $37-43$ & 3 & 671 & $9.8 \pm 0.2$ \\
\hline$>60$ & 4 & 292 & $10.0 \pm 0.5$ \\
\hline
\end{tabular}



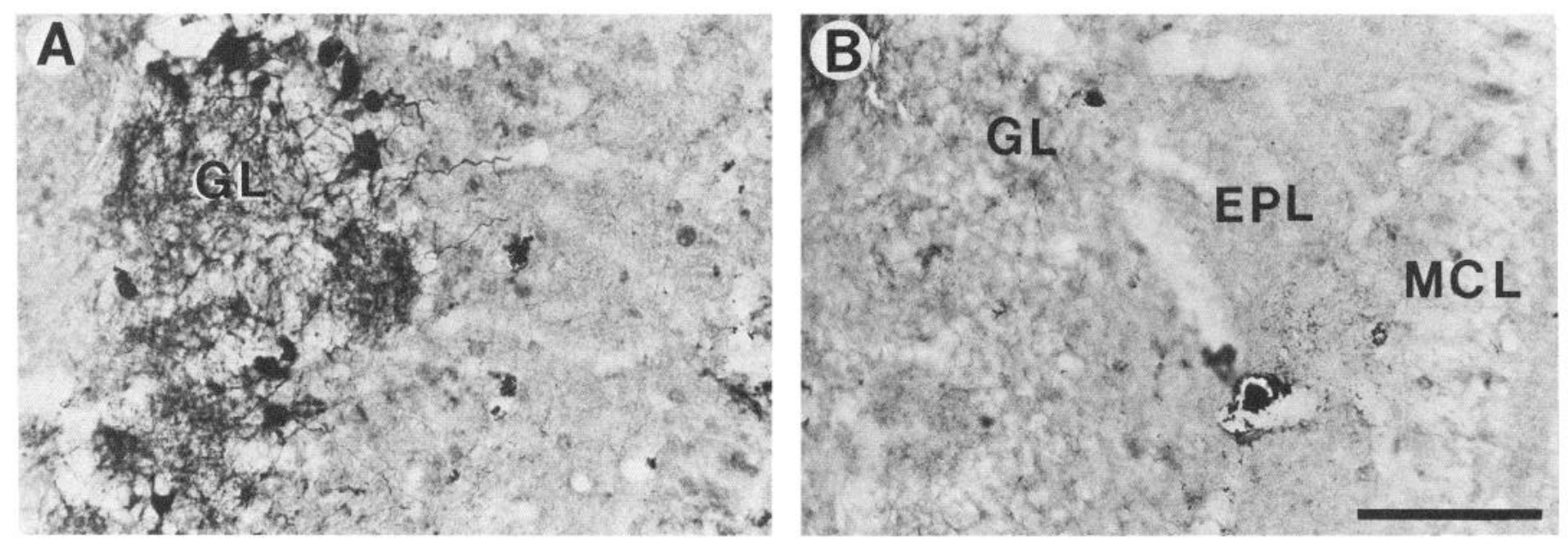

Figure 4. Bright-field photomicrographs of olfactory bulb sections stained to visualize TOH-IR neurons in a P15 rat, one week after the olfactory nerve was lesioned using $\mathrm{ZnSO}_{4}$. $A$, Contralateral to the lesion; $B$, ipsilateral to the lesion.

the medial and lateral sides of the bulb are significantly larger than those located ventrally, dorsally, and at the rostral pole of the bulb.

TOH immunoreactivity. Immunocytochemical expression of TOH is most prevalent in periglomerular and external tufted neurons located around glomeruli in the main olfactory bulb. Collectively these cells are named juxtaglomerular cells. TOHIR staining is infrequently present in middle tufted cells and only rarely in cells located in the mitral cell or granule cell layer. This corresponds very well to previous descriptions of the adult rat (Halasz et al., 1977, 1981; Baker et al., 1983; Seroogy et al., 1985) and hamster (Davis and Macrides, 1983). The most striking feature of the staining is that the TOH-IR cells form a ring around glomeruli, to the extent that their presence helps demarcate glomeruli. On average, 16-17 neurons surround each cross-sectional glomerular profile in the adult. The dendrites of these juxtaglomerular DA neurons ramify almost exclusively within the glomeruli.

\section{Olfactory nerve lesions}

Following $\mathrm{ZnSO}_{4}$ lesions of the nasal epithelium in P3-7 animals, the olfactory bulb ipsilateral to the lesion contained very few TOH-IR neurons compared with the contralateral bulb (Fig. 4) and littermate controls. We did not determine if the olfactory nerve lesions were complete. However, the ipsilateral nerve

\section{Table 2. Estimates of the number of TOH-IR neurons in the MOB} during development

\begin{tabular}{lllll} 
& $\begin{array}{l}\text { Approxi- } \\
\text { mate } \\
\text { length of } \\
\text { olfactory } \\
\text { bulb } \\
(\mathrm{mm})\end{array}$ & $\begin{array}{l}\text { Number } \\
\text { of } 30 \mu \mathrm{m} \\
\text { sections/ } \\
\text { olfactory } \\
\text { bulb }\end{array}$ & $\begin{array}{l}\text { Number of } \\
\text { TOH-IR } \\
\text { cells/30 } \mu \mathrm{m} \\
\text { section }\end{array}$ & $\begin{array}{l}\text { Estimated number } \\
\text { of TOH-IR neurons/ } \\
\text { olfactory bulb }\end{array}$ \\
$\begin{array}{l}\text { Age } \\
\text { (d) }\end{array}$ & 1.25 & 40 & $20-60$ & $800-2400$ \\
\hline $1-2$ & 2.0 & 70 & $50-100$ & $3500-7000$ \\
8 & 2.3 & 75 & $130-250$ & $10,000-18,000$ \\
$14-15$ & 2.5 & 80 & $450-500$ & $35,000-40,000$ \\
22 & 3.5 & 120 & $650-800$ & $75,000-100,000$ \\
$37-40$ & 4.0 & 130 & $750-1110$ & $100,000-150,000$ \\
$>60$ & 4.0 & & &
\end{tabular}

layer and olfactory bulb were greatly reduced in size, indicating successful total or partial destruction of the epithelium. Some faint TOH immunoreactivity could still be observed in many ipsilateral juxtaglomerular neurons 1 week after the operation, but very few neurons had TOH immunoreactivity equaling that found on the contralateral side. We conclude that if the olfactory nerve does not reach the glomeruli during development, then the DA neurons fail to express the TOH phenotype. Therefore, the olfactory nerve is important for the initial expression of TOH. We have not determined whether the olfactory nervedeprived juxtaglomerular neurons remain viable without ever getting the PON input.

\section{Development of olfactory bulb DA neurons}

Certain trends were observed in the development of neurons expressing TOH activity in the MOB.

Cell number. The most salient observation is that at all ages, from neonate to adult, TOH-IR neurons in MOB are associated with the glomerular layer. Another obvious trend is that the number of TOH-IR neurons increases steadily from birth to adulthood. In 30- $\mu \mathrm{m}$-thick frozen sections taken from middle levels of MOB, the DA cell numbers increase linearly $(R=$ 0.945 ) at a rate of approximately 17 cells/d at least until around P60 and then the numbers remain relatively constant during young adulthood (Fig. 5; aged animals have not yet been analyzed). Thus, there is a linear increase in the number of neurons expressing $\mathrm{TOH}$ per section throughout development. There was no indication of periods of unusually high or low rates of increase in TOH expression at any time during development, nor were there any obvious systematic regional differences in TOH expression: neither medial to lateral, dorsal to ventral (Fig. 3) nor rostral to caudal gradients in the expression of the dopamine phenotype were observed. Therefore, it appears that the TOH-IR neurons begin to express the TOH phenotype uniformly in glomeruli in all regions of MOB.

The total number of TOH-IR neurons in MOB at different developmental ages was estimated by calculating the average size of olfactory bulbs and average number of TOH-IR cells per section at each stage. From birth to adulthood we estimate that the increase in TOH-IR neurons in each olfactory bulb is 100to 150 -fold from approximately 1000 at birth to 150,000 in the 
adult (Table 2). The average number of TOH-IR neurons per glomerular profile also increases substantially. Generally, younger rats, P1-2 have 0-3 neurons associated with a glomerular profile. $\mathrm{P} 4$ rats have $1-5$ neurons/glomerular profile, $P 8$ rats have 3-7 neurons, $\mathrm{P} 14$ rats have $4-12$ neurons, $\mathrm{P} 28$ rats have 7-17 neurons, while P37 rats and adults have 14-30 neurons surrounding each glomerulus in a given profile. The glomeruli are somewhat difficult to diffcrentiate in the first week, but it is clear that they do increase in size from birth to adulthood. Interestingly, by the second week, glomeruli can be unambiguously identified in Nissl material, and there are approximately 55-90 glomerular profiles per section taken from the largest part of the MOB; this range remains relatively constant through subsequent developmental stages to adulthood. Thus, at least from week 2 , the number of glomeruli in each section does not increase with age, but the average size of glomeruli and the olfactory bulb continue to increase until at least P60.

Cell types. Previous studies have suggested that there are 2 populations of DA neurons in the adult MOB, based on size or location (Halasz et al., 1981; Baker, 1986). Based on size histograms alone, we could not detect subpopulations within the adult juxtaglomerular DA population, i.e., the size-frequency distribution of DA neurons in adult bulbs was unimodal (Fig. $6 B)$. However, when location was taken into account, we found significant differences in the adult DA population: DA neurons located in the external plexiform layer were significantly larger $(\bar{x}=12.1 \pm 0.7 \mu \mathrm{m}, p<0.05)$ than those with a juxtaglomerular location $(\bar{x}=10.0 \pm 0.5 \mu \mathrm{m})$. Furthermore, juxtaglomerular DA neurons located on the deep half of glomeruli were significantly larger $(\bar{x}=10.6 \pm 0.8 \mu \mathrm{m}, p<0.05)$ than those $(\bar{x}=$ $9.3 \perp 0.4 \mu \mathrm{m}$ ) located around the superficial half of glomeruli.

There is a gradual decrease in the average size of DA neurons after the first postnatal week (Table 1). The decrease in the size of the neurons was significant $(t=5.6, p<0.05)$ when P8 neurons ( $n=5$ rats) were compared with adult neurons ( $n=$ 5). Size-frequency histograms of P8 and adult juxtaglomerular DA neurons showed unimodal bell-shaped curves for each population. However, there was a shift in the average sizes of the neurons such that over $70 \%$ of the DA neurons at P8 were larger than $11 \mu \mathrm{m}$, while in the adult only about $20 \%$ of the juxtaglomerular DA neurons were larger than $11 \mu \mathrm{m}$ (Fig. $6 A-C$ ). Although the proportion of larger DA neurons decreases in the adult bulb compared with the neonate, there are still many of the larger neurons present, particularly in deep juxtaglomerular or external plexiform layer positions. Thus, there appears to be a change in the DA neuronal population with development. As will be argucd bclow, this change probably reflects the later development of smaller, more superficial DA neurons.

\section{Discussion}

\section{Developmental expression of $D A$ neurons in $M O B$}

During development, olfactory bulb neurons destined to express the dopamine phenotype are born in the ventricular or subependymal zone and migrate to their destinations in the most superficial cell layers of the bulb (Hinds, 1968; Altman, 1969; Bayer, 1983; Kishi, 1987). The major finding of the present study was that DA neurons never express the TOH phenotype at the time of birth or during their migration from the proliferative zone through the deep layers of the bulb, but only after they have reached their destination in or immediately subjacent to the glomerular layer. Thus, the transmitter phenotype of this population of CNS neurons appears to be developmentally reg-

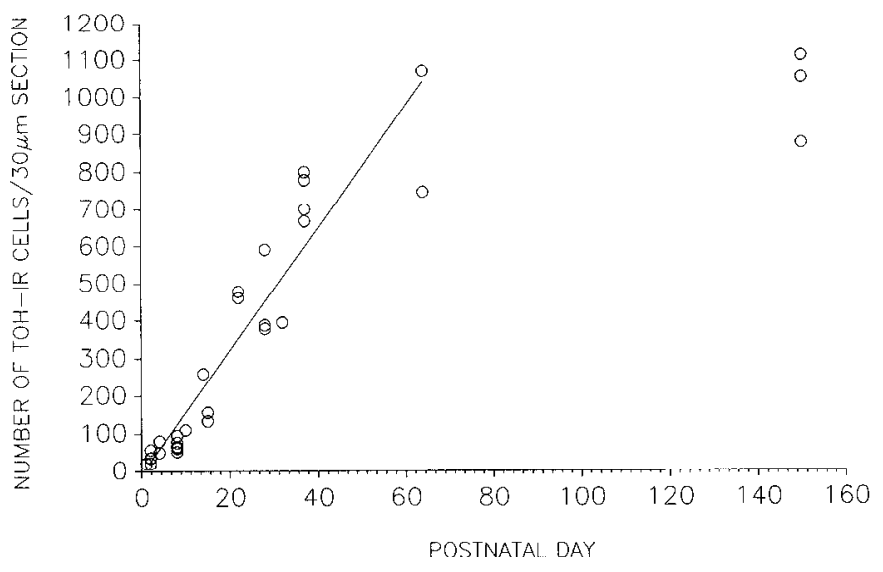

Figure 5. Graph showing an estimate of the number of DA neurons in 30- $\mu \mathrm{m}$-thick transverse sections during development. Fach point represents the number of neurons observed in individual sections taken through a middle rostrocaudal level of MOB. The line represents the slope of a linear regression $(R=0.945)$ of the increase in neurons between birth and P64.

ulated by postmitotic, postmigrational events. We hypothesize that these interneurons only cxpress the TOH phenotype after they insert into their definitive circuit matrix. Thus, it is likely that the trigger for $\mathrm{TOH}$ expression in $\mathrm{MOB}$ is some factor spatially restricted to the glomerular layer.

Such a developmental sequence for $\mathrm{TOH}$ expression may not be universal for CNS neurons. For example, many neurons in the pros-, mes-, and rhombencephalon express TOH immunoreactivity when they are still migrating (Specht et al., 1981a). It might be argued, therefore, that $\mathrm{TOH}$ expression in these neurons is independent of target-afferent interactions since expression is observed during their migration. The difficulty with this interpretation is that it is not known whether brainstem DA neurons have contacts with their eventual targets and/ or receive synaptic inputs from their definitive afferents while they are still migrating. In the case of the olfactory bulb it is conceivable that migrating pre-DA neurons have made contacts, but it is most likely that these interneurons do not establish adultlike circuit connections until they reach the glomeruli. Thus, the apparent discrepancy between brain-stem neurons that express TOH during migration and MOB neurons whose TOH expression is postmigratory may not be an essential difference because brain-stem neurons may make and/or receive contacts during migration. The key issue is whether the transmitter phenotype is triggered by specific cell-cell interactions in the glomeruli, and further studies, including EM analysis, are needed.

The triggering of the dopamine phenotype in the juxtaglomerular region may indicate that the neurons require an input from the primary olfactory neurons since the olfactory nerve terminates heavily and exclusively in the glomeruli. Indeed, in the MOB of the adult rat, the maintenance of DA synthesis in periglomerular cells depends upon integrity of primary olfactory afferent input to MOB (Nadi et al., 1981; Baker et al., 1983, 1984). Thus, when the PON input to MOB is removed, TOH expression is reduced or abolished in juxtaglomerular cells (Baker et al., 1983, 1984). However, the loss of the PON input does not seem to affect the viability of the juxtaglomerular cells, and many appear to regain their DA phenotype when PON axons regenerate into the glomeruli (Baker et al., 1983, 1984).

Antibodies to olfactory marker protein have been used in 
Figure 6. Frequency histograms showing the size distribution of DA neurons in $(A)$ PND $8 \mathrm{MOB},(B)$ adult juxtaglomerular neurons, $(C$ ) PND 8 and adult compared, and $(D)$ neurons in the adult external plexiform layer $(E P L)$. The histograms were generated from the total number of neurons in all animals observed ( $2-3$ sections/animal, 4-5 animals/histogram).
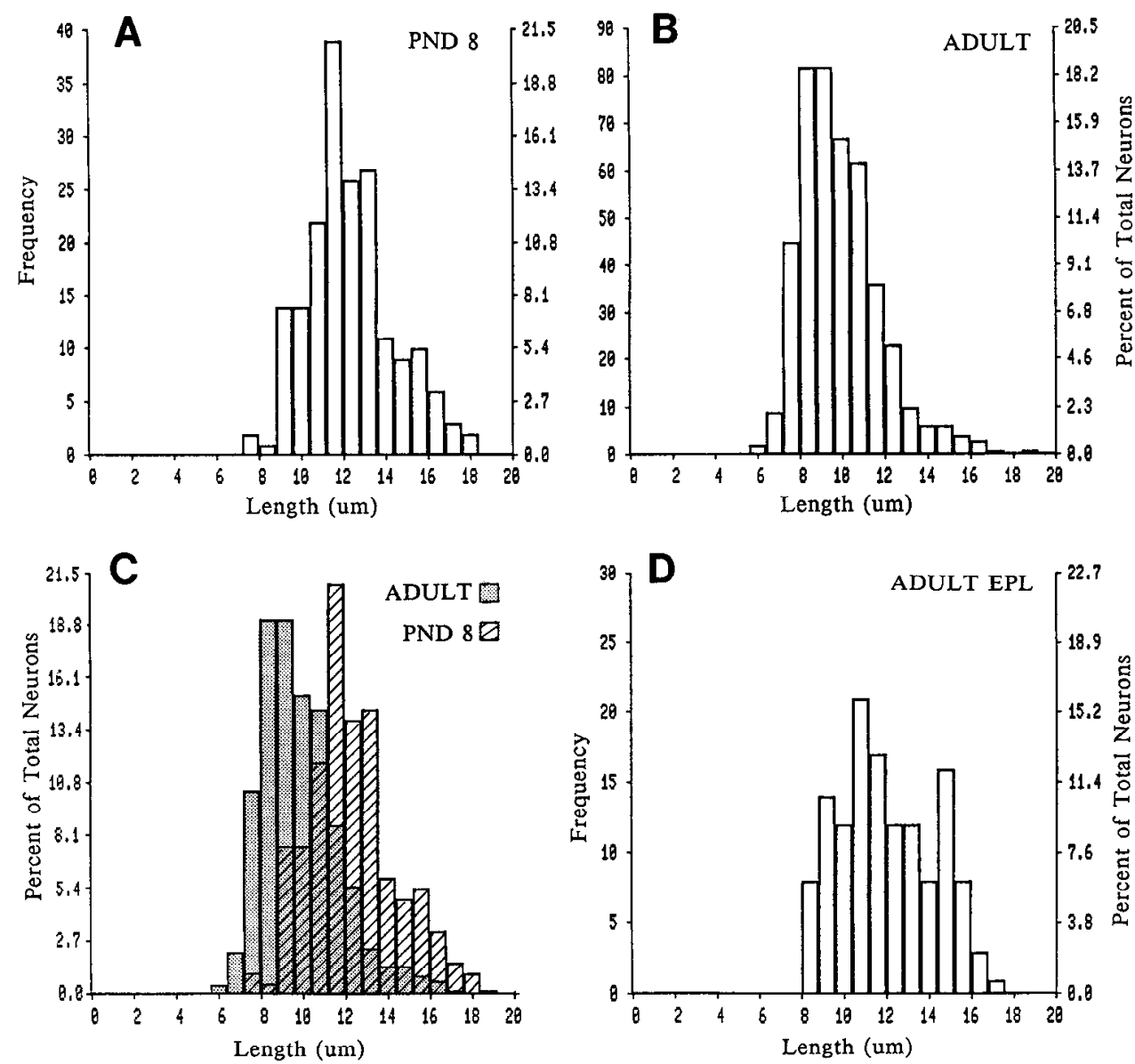

studies as markers for maturity and, hence, synaptic connection between primary olfactory neurons and the olfactory bulb in the rat (Farbman and Margolis, 1980). These studies indicated that the first connections between epithelium and olfactory bulb are made $1-3 \mathrm{~d}$ before birth, and the intensity and staining patterns continue to increase until 1 month after birth. Recent studies confirm through electron microscopic observation that the first synapses form in the glomerular layer at embryonic day 18 (A. Farbman, personal communication). The progressive developmental increase in the PON connections with the olfactory bulb thus parallels the increase in TOH-IR neurons around glomeruli during development. Therefore, PON axons appear to be important for the developmental induction of the $\mathrm{TOH}$ phenotype in juxtaglomerular cells. Our nasal $\mathrm{ZnSO}_{4}$ lesions drastically reduced the PON inputs to the developing MOB and reduced TOH expression in juxtaglomerular cells, further suggesting that the PON input is necessary (but not necessarily sufficient) for the initiation of $\mathrm{TOH}$ expression.

Another indication of the importance of PON input for the initiation of DA expression is the temporal relationship between neuron birth and the expression. The expression of TOH phenotype lags somewhat behind the birth curve of periglomerular neurons (Bayer, 1983). For example, most periglomerular neurons are born by $\mathrm{P} 14$, the majority being generated in or prior to the first postnatal week (Bayer, 1983). A few TOH-IR neurons are present in the MOB before birth (Specht et al., 1981b), but most DA neurons in the MOB do not express the TOH phenotype until after birth, and it is a gradual steady increase that does not peak until about the 7 th postnatal week. Thus, since most periglomerular cells are born in the first 2 postnatal weeks (Bayer, 1983), most of them are probably migrating or may already be in the glomeruli several weeks before they begin to express immunocytochemically detectable levels of TOH. The gradual increase in TOH-IR cells, thus, appears to correlate well with glomerular maturation and gradual increase in PON inputs to MOB during development (Farbman and Margolis, 1980) and not as much with time of birth or migration of the periglomerular neurons.

\section{Mechanism of TOH expression}

The foregoing discussion strongly suggests that the initial $\mathrm{TOH}$ expression requires olfactory nerve input. However, it is not known if the regulatory effect of the olfactory nerve on $\mathrm{TOH}$ expression is mediated via pre- or postsynaptic mechanisms or both. In the PNS, both pre- and postsynaptic regulation of $\mathrm{TOH}$ expression have been reported (Black, 1978; Katz and Black, 1986); preganglionic axons in the sympathetic system have regulatory effects on postsynaptic postganglionic TOH-IR cells (Black, 1978), while TOH expression in pseudounipolar neurons in the petrosal ganglion appears to be influenced by their peripheral target, the carotid body (Katz and Black, 1986). In the olfactory bulb, it is not known whether PON axons terminate directly on the juxtaglomerular DA neuron. Electron microscopic studies indicate that PON terminals contact the dendrites of periglomerular, external tufted cells and mitral cells (Shepherd, 1972). Thus, it is possible that TOH expression is triggered and maintained by PON contacts on DA neurons. On the other hand, periglomerular and tufted cells have been reported to 
express neurotransmitters and peptides other than dopamine (Seroogy et al., 1985; Baker, 1986; Gall et al., 1986). At least 2 laboratories have reported that some periglomerular neurons coexpress DA and GABA in the adult rat (Kosaka et al., 1985, 1987b; Gall et al., 1987) and during development (Kosaka et al., 1987a). However, there have been no EM immunocytochemical studies of the relations between chemically identified neurons and synapses in the glomerular layer. Thus, while PONs may synapse directly on DA neurons, it is also possible that PONs contact non-DA periglomerular neurons and, thus, influence $\mathrm{TOH}$ expression via an action on periglomerular neurons that are the targets of periglomerular DA neurons. A third possibility is that PONs contact centrifugal afferent terminals that are presynaptic to DA periglomerular neurons. We have recently demonstrated a dense serotonergic input to the glomeruli from the raphe nuclei (McLean and Shipley, 1987a, b) and heavy cholinergic input from the basal forebrain (Shipley et al., 1986; and in preparation). It is not known whether these centrifugal fibers terminate on DA neurons nor whether PON axons are presynaptic to centrifugal terminals. Thus, while there is good evidence that the olfactory nerve is necessary for the initiation (this report) and maintenance (Kawano and Margolis, 1982; Baker et al., 1983, 1984) of TOH expression in MOB DA neurons, it is unclear whether this regulatory action is due to a direct action of PON terminals on DA neurons or indirect actions mediated via PON contacts upon postsynaptic targets of DA neurons or on afferents presynaptic to the DA neurons.

The best studied example of synaptic regulation of $\mathrm{TOH}$ is in the PNS (Black and Geen, 1974), in which it has been shown that cholinergic synapses acting on nicotinic receptors regulate postsynaptic TOH. A similar mechanism might operate in the olfactory bulb, as we have recently shown that there are cholinergic inputs to the glomerular layer (Shipley et al., 1986; and in preparation) and the glomerular layer contains dense binding of nicotinic, but not muscarinic, receptor ligands (Blaha et al., 1984). Further study is necessary to determine whether this nicotinic synapse interacts with the DA neurons and/or the olfactory nerve input.

\section{Sensitivity of TOH staining}

A potential objection to our interpretation that TOH expression is triggered by some factor relating to the glomerular layer is that our immunohistochemical procedure may not be sensitive enough to detect extremely low levels of $\mathrm{TOH}$ in the tissue sections. Although lack of sensitivity is possible, changes in levels of TOH-IR neuron expression appears to correlate well with published biochemical measures of TOH and dopamine activity in the MOB (Nadi et al., 1981). Second, if migrating neurons have low levels of $\mathrm{TOH}$, then the levels in at least some of them should have been detected by immunohistochemistry. Unless the levels of the enzyme are very tightly regulated in every neuron, the sheer magnitude of the population would lead one to expect that at least a small percentage of the cells would have immunocytochemically detectable levels of $\mathrm{TOH}$ during their migration. TOH expression in migrating neurons was never observed, leading us to suggest that the phenotype is not triggered until the neurons have reached their destination. Even if low levels of $\mathrm{TOH}$ are present in migrating neurons, it still appears that events associated with the neurons reaching the glomerular layer must trigger a large increase in $\mathrm{TOH}$ expression because lesions of the cpithclium during the initial postnatal week cause a drastic reduction in the number of $\mathrm{TOH}$-positive neurons observed in the second postnatal week. Thus, we hypothesize that expression occurs only after the neurons have reached their target layer. Clearly, it will be important to pursue this issue further. One way to do this may be to determine whether TOH RNA expression is initiated when the neurons reach the glomeruli. In situ hybridization techniques using probes for TOH mRNA might shed additional light on this question.

\section{Position and size relationships of periglomerular cells}

TOH-IR neuron sizes and their juxtaglomerular distribution change during development. We observed that most of the TOHIR neurons are located on the deep portion of the glomeruli in early postnatal development, whereas by adulthood the neurons surround the glomeruli. However, we were unable to determine if the TOH-IR neurons that are observed around the deep portion of the glomeruli in the neonate migrate to more superficial juxtaglomerular positions or whether they remain set in the deep position through adulthood and comprise the later-arriving superficially located cells. TOH-IR neurons in the neonate were generally larger than the average size of TOH-IR juxtaglomerular ncurons at later stages of development. In addition, we observed that in older animals deeply placed DA neurons are larger than more superficially located DA neurons. It is possible, therefore, that the first juxtaglomerular neurons in the MOB to express $\mathrm{TOH}$ activity are the larger, more deeply located external tufted cells. In such a scheme, as development continues, smaller, more superficially located and later-born periglomerular neurons would begin to express the DA phenotype; the increasing number of smaller neurons would account for the average decrease in size of TOH-IR neurons that surround glomeruli.

\section{Function of $D A$ neurons in the developing $M O B$}

We have estimated that there are well over 100,000 DA neurons in MOB of the adult rat. The biological significance of these DA neurons is unknown, but their sheer number and the fact that they are positioned at the first level of synaptic integration in the olfactory system argues that their importance to physiological processing in MOB must be substantial. The role of DA neurons in development is also unclear. However, the gradual increase in the number of neurons that express TOH-IR in the bulb may correlate with the animal's gradual ability to detect and discriminate odors (Alberts, 1976, 1981).

In some other parts of the brain, including the di-, mes-, and rhombencephalon, TOII-IR cells appear very early in development and have been proposed to have a trophic role (Specht et al., 1981a). However, in the MOB, TOH expression is relatively late in development, and, therefore, it is unlikely that these cells have significant trophic or inductive roles in the bulb. On the other hand, these DA neurons may play a role in synaptic stabilization. DA has been shown to inhibit growth cones in retinal neurons (Lankford et al., 1986). If a similar mechanism operates in the bulb, DA neurons may function to stabilize developing and replacement PON synapses, as there is some turnover of PONs and their glomerular synapses throughout the life of the animal (Graziadei and Monti Graziadei, 1978a, b).

In summary, we have shown that there is a steady increase in the number of neurons expressing TOH-IR in the developing rat olfactory bulb. The olfactory nerve is necessary for the initiation (present study) and maintenance (Margolis et al., 1974; Nadi ct al., 1981; Baker et al., 1983, 1984; Kream et al., 1984) of the TOH expression in MOB DA neurons, suggesting that 
specific cell-cell interactions underlie the regulation of this neuron's transmitter phenotype. Whether epigenetic factors such as cell-cell interactions are fundamental to the induction or maintenance of transmitter phenotype in other central neuronal populations is not known, but the potential for the principles operating for olfactory bulb DA neurons to be a general phenomena is intriguing. The present study provides a chemoanatomical framework for further investigating the specific developmental events that regulate $\mathrm{TOH}$ expression in one well-defined population of CNS DA neurons and provides an example of postmitotic, postmigrational induction of a CNS transmitter phenotype that may be common to other transmitter systems.

\section{References}

Alberts, J. R. (1976) Olfactory contributions to behavioral development in rodents. In Mammalian Olfaction, Reproductive Processes and Behavior, R. L. Doty, ed., pp. 67-95, Academic, New York.

Alberts, J. R. (1981) Ontogeny of olfaction: Reciprocal roles of sensation and behavior in the development of perception. In Development of Perception; Psychobiological Perspectives, Vol. 1, R. N. Aslin, J. R. Alberts, and M. R. Petersen, eds., pp. 322-357. Academic, New York.

Altman, J. (1969) Autoradiographic and histological studies of postnatal neurogenesis. IV. Cell proliferation and migration in the anterior forebrain with special reference to persisting neurogenesis in the olfactory bulb. J. Comp. Neurol. 137: 433-458.

Baker, H. (1986) Species differences in the distribution of substance $P$ and tyrosine hydroxylase immunoreactivity in the olfactory bulb. J. Comp. Neurol. 252: 206-226.

Baker, H., T. Kawano, F. L. Margolis, and T. H. Joh (1983) Transneuronal regulation of tyrosine hydroxylase expression in olfactory bulb of mouse and rat. J. Neurosci. 3: 69-78.

Baker, H., T. Kawano, V. Albert, T. H. Joh, D. J. Reis, and F. L. Margolis (1984) Olfactory bulb dopamine neurons survive deafferentation-induced loss of tyrosine hydroxylase. J. Neurosci. 11: 605615.

Bayer, S. A. (1983) ${ }^{3} \mathrm{H}$-Thymidine-radiographic studies of neurogenesis in the rat olfactory bulb. Exp. Brain Res. 50: 329-340.

Black, I. B. (1978) Regulation of autonomic development. Annu. Rev. Neurosci. 1: 183-214.

Black, I. B., and S. C. Geen (1974) Inhibition of the biochemical and morphological maturation of adrenergic neurons by nicotinic receptor blockade. J. Neurochem. 22: 301-306.

Blaha, G., W. Blair, W. T. Nickell, and M. T. Shipley (1984) Cholinergic $(\mathrm{CH})$ receptors in the rat olfactory bulb: Nicotinic $(\mathrm{N})$ and muscarinic (M) cholinergic receptors are segregated and coincide with acetylcholinesterase (AChE). Soc. Neurosci. Abstr. 14: 341.8.

Brunjes, P. C., L. K. Smith-Crafts, and R. McCarty (1985) Unilateral odor deprivation: Effects on the development of olfactory bulb catecholamines and behavior. Brain Res. 354: 1-6.

Davis, B. J., and F. Macrides (1983) Tyrosine hydroxylase immunoreactive neurons and fibers in the olfactory system of the hamster. J. Comp. Neurol. 214: 427-440.

Farbman, A. I., and F. L. Margolis (1980) Olfactory marker protein during ontogeny: İmmunocytochemical localization. Dev. Biol. 74: 205-215.

Furshpan, E. J., P. R. MacLcish, P. H. O'Laguc, and D. D. Potter (1976) Chemical transmission between rat sympathetic neurons and cardiac myocytes developing in microcultures: Evidence for cholinergic, adrenergic, and dual-function neurons. Proc. Natl. Acad. Sci. USA 73: $4225-4229$.

Gall, C., K. M. Seroogy, and N. Brecha (1986) Distribution of VIPand NPY-like immunoreactivities in rat main olfactory bulb. Brain Res. 374: 389-394.

Gall, C. M., S. H. C. Hendry, K. B. Seroogy, E. G. Jones, and J. W. Haycock (1987) Evidence for coexistence of GABA and dopamine in neurons of the rat olfactory bulb. J. Comp. Neurol. 266: 307-318.

Graziadei, P. P. C., and G. A. Monti Graziadei (1978a) Continuous nerve cell renewal in the olfactory system. In Handbook of Sensory Physiology, Vol. 9, M. Jacobson, ed., pp. 55-82, Springer-Verlag, Berlin.

Graziadei, P. P. C., and G. A. Monti Graziadei (1978b) The olfactory system: A model for the study of neurogenesis and axon regeneration in mammals. In Neuronal Plasticity, C. W. Cotman, ed., pp. 131153, Raven Press, New York.

Halasz, N., A. Ljungdahl, T. Hökfelt, O. Johansson, M. Goldstein, D. Park, and P. Biberfeld (1977) Transmitter histochemistry of the rat olfactory bulb. I. Immunohistochemical localization of monoamine synthesizing enzymes. Support for intrabulbar, periglomerular dopamine neurons. Brain Res. 126: 455-474.

Halasz, N., O. Johansson, T. Hökfelt, A. Ljungdahl, and M. Goldstein (1981) Immunohistochemical identification of two types of dopamine neuron in the rat olfactory bulb as seen by serial sectioning $\mathrm{J}$. Neurocytol. 10: 251-259.

Hinds, J. W. (1968) Autoradiographic study of histogenesis in the mouse olfactory bulb. I. Time of origin of neurons and neuroglia. J. Comp. Neurol. 134: 287-304

Katz, D. M., and I. B. Black (1986) Expression and regulation of catecholaminergic traits in primary sensory neurons: Relationships to target innervation in vivo. J. Neurosci. 6: 983-989.

Kawano, T., and F. L. Margolis (1982) Transsynaptic regulation of olfactory bulb catecholamines in mice and rats. J. Neurochem. 39: 342-348.

Kishi, K. (1987) Golgi studies on the development of granule cells of the rat olfactory bulb with reference to migration in the subependymal layer. J. Comp. Neurol. 258: 112-124.

Kosaka, T., Y. Hatuguchi, K. Hama, I. Nagatsu, and J.-Y. Wu (1985) Coexistence of immunoreactivities for glutamate decarboxylase and tyrosine hydroxylase in some neurons in the periglomerular region of the rat olfactory bulb; possible coexistence of gamma-aminobutyric acid (GABA) and dopamine. Brain Res. 343: 166-171.

Kosaka, K., K. Hama, I. Nagatsu, J.-Y. Wu, O. P. Ottersen, J. StormMathisen, and T. Kosaka (1987a) Postnatal development of neurons containing both catecholaminergic and GABAergic traits in the rat main olfactory bulb. Brain Res. 403: 355-360.

Kosaka, T., K. Kosaka, C. W. Heizmann, I. Nagatsu, J.-Y. Wu, N. Yanaihara, and K. Hama (1987b) An aspect of the organization of the GABAergic system in the rat main olfactory bulb: Laminar distribution of immunohistochemically defined subpopulations of GABAergic neurons. Brain Res. 411: 373-378.

Kream, R. M., B. J. Davis, T. Kawano, F. L. Margolis, and F. Macrides (1984) Substance $P$ and catecholaminergic expression in neurons of the hamster main olfactory bulb. J. Comp. Neurol. 222: 140-154.

Lankford, K. L., F. G. DeMello, and W. L. Klein (1986) Transient D1 receptor mediates dopamine inhibition of growth cone motility and neurite outgrowth in a subset of vertebrate CNS neurons. Soc. Neurosci. Abstr. 12: 1116.

LeDouarin, N. M. (1980) Migration and differentiation of neural crest cells. Curr. Top. Dev. Biol. 16: 31-85.

Margolis, F. L., M. Roberts, D. Ferriero, and J. Feldman (1974) Denervation in the primary olfactory pathway of mice: Biochemical and morphological effects. Brain Res. 81: 469-483.

McLean, J. H., and M. T. Shipley (1987a) Serotonergic afferents to the rat olfactory bulb. I. Origins and laminar specificity of serotonergic inputs in the adult rat. J. Neurosci. 7: 3016-3028.

McLean, J. H., and M. T. Shipley (1987b) Serotonergic afferents to the rat olfactory bulb. II. Changes in fiber distribution during development. J. Neurosci. 7: 3029-3039.

Morita, Y., and T. E. Finger (1987) Area postrema of the goldfish, Carassius auratus: Ultrastructure, fiber connections, and immunohistochemistry. J. Comp. Neurol. 256: 104-116.

Nadi, N. S., R. Head, M. Grillo, J. Hempstead, N. Grannot-Reisfeld, and F. L. Margolis (1981) Chemical deafferentation of the olfactory bulb: Plasticity of the levels of tyrosine hydroxylase, dopamine and norepinephrine. Brain Res. 213: 365-377.

Potter, D. D., S. C. Landis, and E. J. Furshpan (1981) Adrenergiccholinergic dual function in cultured sympathetic neurones of the rat. In Development of the Automatic Nervous System (Ciba Found. Symp. 83), K. Elliot and G. Lawrenson, eds., pp. 123-138, Pitman, London.

Reichardt, L. F., and P. H. Patterson (1977) Neurotransmitter synthesis and uptake by isolated sympathetic neurones in microcultures. Nature 270: 147-151.

Serongy, K. B., N. Brecha, and C. Gall (1985) Distribution of cholecystokinin-like immunoreactivity in the rat main olfactory bulb. J. Comp. Neurol. 239: 373-383.

Shepherd, G. M. (1972) Synaptic organization of the mammalian olfactory bulb. Physiol. Rev. 52: 864-917. 
Shimada, M. (1966) Cytokinetics and histogenesis of early postnatal mouse brain as studied by ${ }^{3} \mathrm{H}$-thymidine autoradiography. Arch. Histol. Jpn. 4: 413-437.

Shipley, M. T., W. T. Nickell, and J. H. McLean (1986) Organization of afferents from the nucleus of the diagonal band to the olfactory bulb. Chem. Senses 11:663.

Specht, L. A., V. M. Pickel, T. H. Joh, and D. J. Reis (1981a) Light- microscopic immunocytochemical localization of tyrosine hydroxylase in prenatal rat brain. I. Early ontogeny. J. Comp. Neurol. 199. 233-253.

Specht, L. A., V. M. Pickel, T. H. Joh, and D. J. Reis (1981b) Lightmicroscopic immunocytochemical localization in prenatal rat brain. II. Late ontogeny. J. Comp. Neurol. 199: 255-276. 